\title{
TOWARDS THE PROBLEM OF DISPERSITY AND MORPHOLOGY OF PARTICLES IN WELDING AEROSOLS
}

\author{
I.P. GUBENYA ${ }^{1}$, I.R. YAVDOSHCHIN ${ }^{1}$, S.N. STEPANYUK ${ }^{1}$ and A.V. DEMETSKAYA ${ }^{2}$ \\ ${ }^{1}$ E.O. Paton Electric Welding Institute, NASU \\ 11 Bozhenko Str., 03680, Kiev, Ukraine. E-mail: office@paton.kiev.ua \\ ${ }^{2}$ Institute of Occupational Health, AMSU \\ 75 Saksagansky Str., 03680, Kiev, Ukraine. E-mail: torovchik@mail.ru
}

\begin{abstract}
The hard component of welding aerosol is one of the main hazards, which are encountered by those working with welding and related technologies. The investigations on this subject have been carried out for more than half a century. The size and dispersity of the particles are of particular interest among the properties and peculiarities of structure of hard component of welding aerosol, as these parameters define the ways of penetrating into a living organism. The present study examines dispersity of particles of hard component of welding aerosol by means of several types of equipment, involving different analysis principles. It was shown that the technique of preparation of a sample for analysis and peculiarities of equipment greatly influence the results. The morphology of particles was also examined. 20 Ref., 5 Figures.
\end{abstract}

$\boldsymbol{K} \boldsymbol{e} \boldsymbol{y} \boldsymbol{w} \boldsymbol{o} \boldsymbol{d} \boldsymbol{s}:$ welding aerosol, hard component, dispersity, morphology, nanoparticle, agglomerate, laser granulometry, diffusion spectrometer

For more than half a century, welding aerosol has been one of the main objects of investigation of negative factors affecting human organism in the process of welding. Nowadays these investigations are of extreme importance in view of new data in medicine and toxicology.

Welding aerosol is a by-product of welding process and consists of hard and gassy components, predetermined by its formation processes. Under high-temperature heating during welding, the components of coating undergo thermal destruction, and some part of base and electrode materials evaporates. As a result of blowing out of the formed gas-vapor mixture into relatively low-temperature environment, condensation of vapor phase occurs and the small hard particles are formed [1]. The primary object of investigation is the hard component of welding aerosol (HCWA), as it contains main hazardous constituents.

The HCWA influence on a living organism (toxicity) is a complex characteristic and depends on many factors, namely size and morphology of single particles or their agglomerates, total quantitative distribution by sizes (dispersity), chemical composition, content of highlytoxic compounds, solubility. Each of these factors should be analyzed separately and in combination with others.
The size of particles is an important factor, which to a great extent determines the HCWA toxicity: solid particles with a diameter of less than $20 \mu \mathrm{m}$ may remain suspended in air flow [2]. Size of single particles and their agglomerates varies from several dozens of nanometers to dozens of micrometers [3-5]. About 70-80\% of particles with a diameter of $0.1-2.0 \mu \mathrm{m}$, which penetrate into organism through respiratory organs, may be removed in breathing out. The particles of coarser size may be removed from the organism by spitting $[6,7]$. The most hazardous are nanosized and submicron particles, which due to their small size may penetrate through skin [8], as well as directly to brain via nerve endings [9-12].

The particles of HCWA are of regular and irregular spherical shape. The majority of particles has heterogeneous structure (particles consist of core and shell) [1, 13, 14], which is predetermined by selectivity of the process of evaporation and condensation (various constituents of high-temperature vapor are condensed at different temperature). First, the condensation of the elements with lower vapor pressure and higher melting temperature (manganese, iron) occurs, and then the elements with higher vapor pressure and lower melting temperature (sodium, potassium, silicon and others) condense. Thickness of shell depends on temperature and oxidation potential of arc atmosphere [1]. Figure 1 shows the appearance of particles and agglomerates of HCWA. 


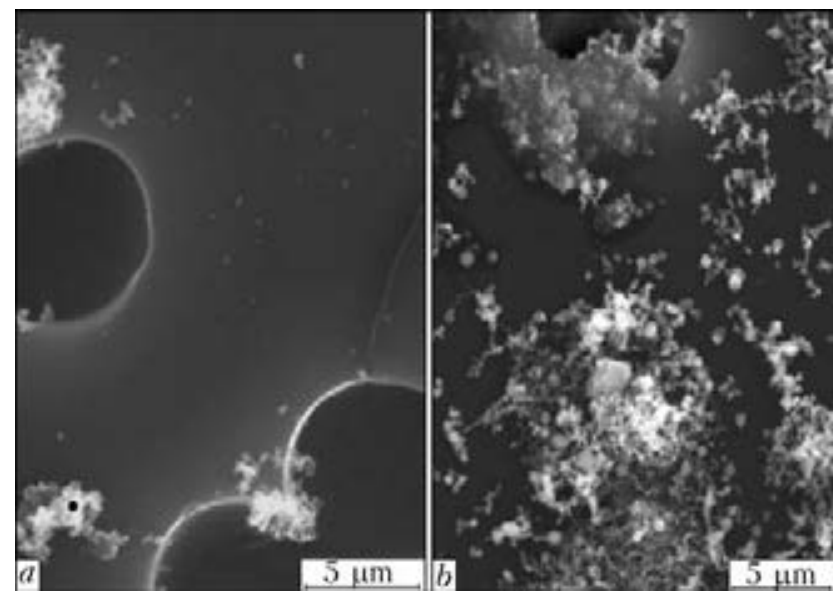

Figure 1. Typical size and morphology of HCWA particles [15]: $a-$ coarse particle with deposition of nanosized particles; $b-$ agglomerates of nanosized particles

Dispersity is analyzed by using several types of equipment, operating on different principles. The aerodynamic separation (Berner and Anderson impactors) $[2-5,15,16]$ is the most widely applied method. The method of measurement of charged particles mobility in electric field (SMPS scanning analyzers) [2, 16, 17] is applied more rarely. Laser granulometry (laser analyzers with flow-through and fixed cells) [18] is relatively new and scarcely applied method.

It is difficult to define the characteristics of single particles in common with their total quantitative distribution by sizes due to the wide range of particle sizes. The substantial drawback of applying aerodynamic separation method is destruction of clusters as a result of collision in their passing through separate levels of the impactor. The drawback of the HCWA analysis, carried out by the method of laser granulometry, is the specifics of technique of preparation and carrying out of analysis, namely mechanical effect on the mass of deposited aerosol in its separating from the filter, use of dispersion medium (usually it

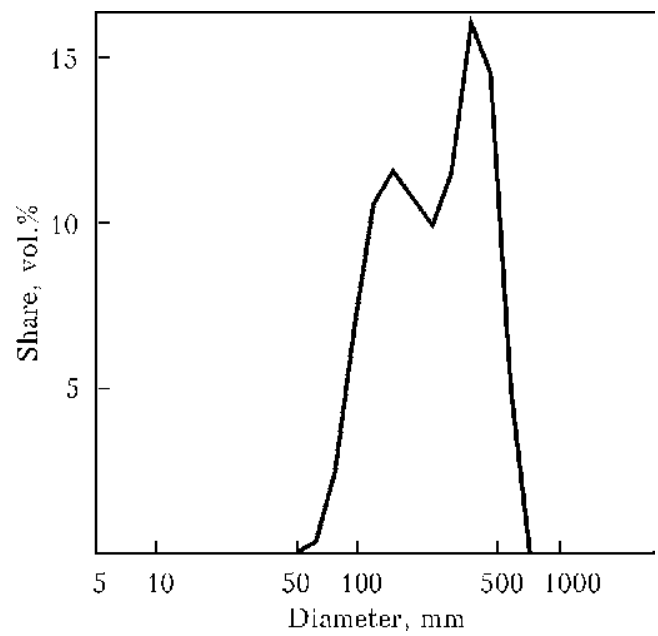

Figure 2. Dispersity of HCWA particles obtained by means of Zetasizer $1000 \mathrm{HS}$ instrument is distilled water with or without surface active agent), and ultrasonic oscillations. The most promising method is the HCWA investigation using equipment, which analyzes the particles directly in air flow, namely diffusion, laser and electrical analyzers.

To examine the morphology of single particles, the electron microscopy is applied (SEM, TEM, EPMA electron probe) $[3,5,7,16,19,20]$. In this case, HCWA is deposited on metal substrates.

To examine the dispersity, the Malvern Zetasizer 1000 HS (Great Britain, measurement range of $0.002-3 \mu \mathrm{m}$, fixed cell), HORIBA LA300 (Japan, measurement range of $0.1-600 \mu \mathrm{m}$, flow-through cell), and AeroNanoTech diffusion aerosol spectrometer DAS 2702 (Russia, measurement range of 3-200 $\mu \mathrm{m}$, analysis in air flow) were used.

It should be mentioned that the equipment for dispersity analysis has limited measurement range, which makes it difficult to get comprehensive and real description of HCWA characteristics.

The first two analyzers are working on the principle of laser granulometry method, while the third one is working on the method of transmission of the air flow with particles through diffusion batteries and determination of deposition (or slippage) coefficient of aerosol particles during passing. In each case, the object of investigation was HCWA, obtained in welding with rutile-type electrodes.

The technique of standard sampling of HCWA (mechanical separation of the aerosol deposited on filter) leads to the formation of «briquette» accumulation, and mechanical disintegration does not allow obtaining the qualitative object for analysis. Thus, the ultrasonic treatment was applied to destroy briquettes.

To carry out the investigation by means of Zetasizer $1000 \mathrm{HS}$, the HCWA, removed from the filter, was crushed mechanically and put into the container, filled with distilled water and surface active agent ( $1 \%$ solution of sodium hexametaphosphate). The suspension was stirred for $10 \mathrm{~min}$ in the UZDN-A ultrasonic disperser, then put in the cuvette, filled with dispersion medium for the two-thirds, and then the analysis was carried out (Figure 2).

The obtained data prove that the HCWA has a bimodal distribution of particles by sizes. The average particle diameter for each spike is 156 and $370 \mathrm{~nm}$.

To analyze by means of HORIBA LA-300, the HCW A sample, obtained by removing the deposited aerosol from filter, was put into the analyzer 


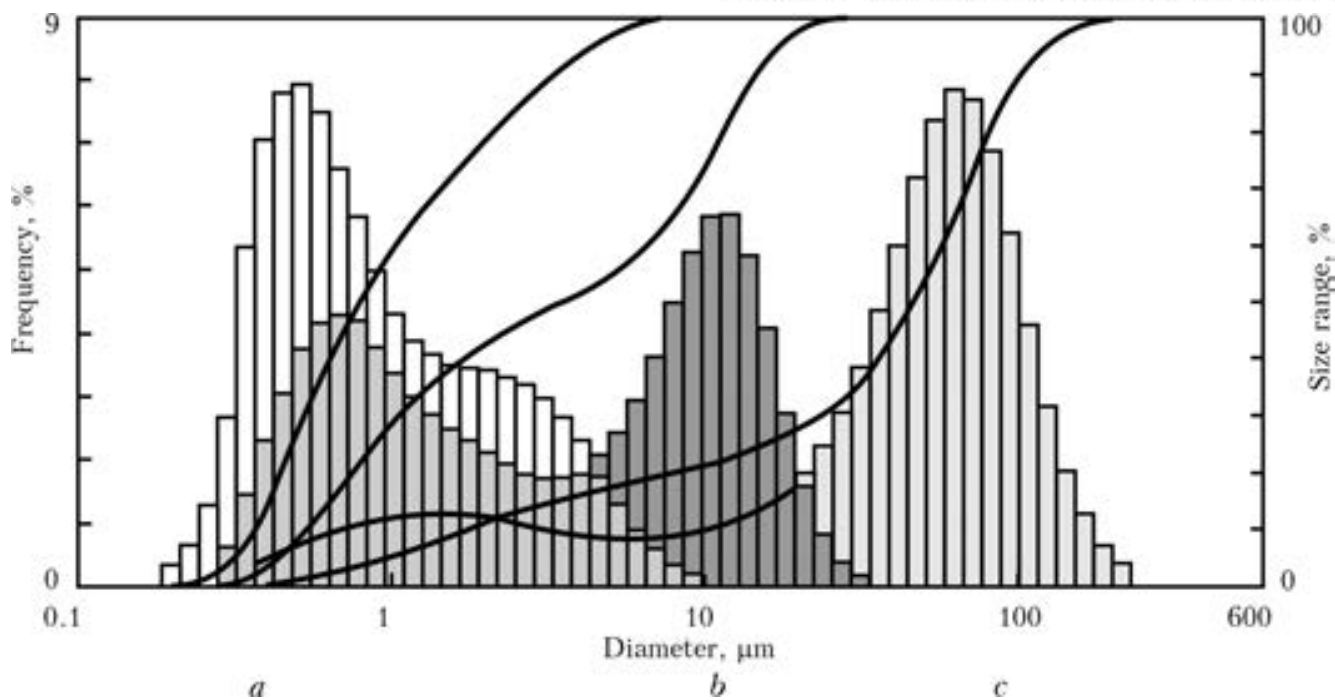

Figure 3. Range of HCWA distribution by sizes after $30 \mathrm{~s}$ ultrasonic treatment $(a)$, at medium speed of purge pump without ultrasonic treatment $(b)$ and at minimum speed of purge pump without ultrasonic treatment $(c)$

cuvette, filled with the distilled water. The analysis of each sample was made in three stages: immediately after sample putting at the minimum speed of the purge pump without ultrasonic treatment; repeatedly at the medium speed of the purge pump without ultrasonic treatment, and at the medium speed of the purge pump after ultrasonic treatment for $30 \mathrm{~s}$.

HCWA sample, after its putting into distilled water, represented rather coarse agglomerates of 50-80 $\mu \mathrm{m}$ average size (Figure 3, spike $c$ ). However, when the speed of the purge pump was increased, the agglomerates were refined to the average size of $10 \mu \mathrm{m}$ (spike $b$ ) and considerable amount of constituents of less than $1 \mu \mathrm{m}$ size appeared. The application of ultrasonic treatment causes their further destruction. As a result, the average size of the fine-dispersed fraction makes up about $0.5-0.6 \mu \mathrm{m}$ (spike $a$ ). In all three cases, the HCWA has a bimodal distribution.

Thus, the samples, obtained by mechanical removing of HCWA from the filter, are hardly suitable for analysis without additional ultrasonic treatment, which duration changes significantly the results of analysis. The further treatment can, probably, provoke the destruction of agglomerates, formed in the air flow, and represent the natural shape of HCWA, that does not make it possible to judge about real sizes of particles and agglomerates.

To investigate the HCWA by means of DAS 2702 , the air intake was realized at the distance of $70-80 \mathrm{~cm}$ from the arc burning zone. The process of analysis started since the moment of arc ignition and continued after completion of arcing till the beginning of substantial total reduction

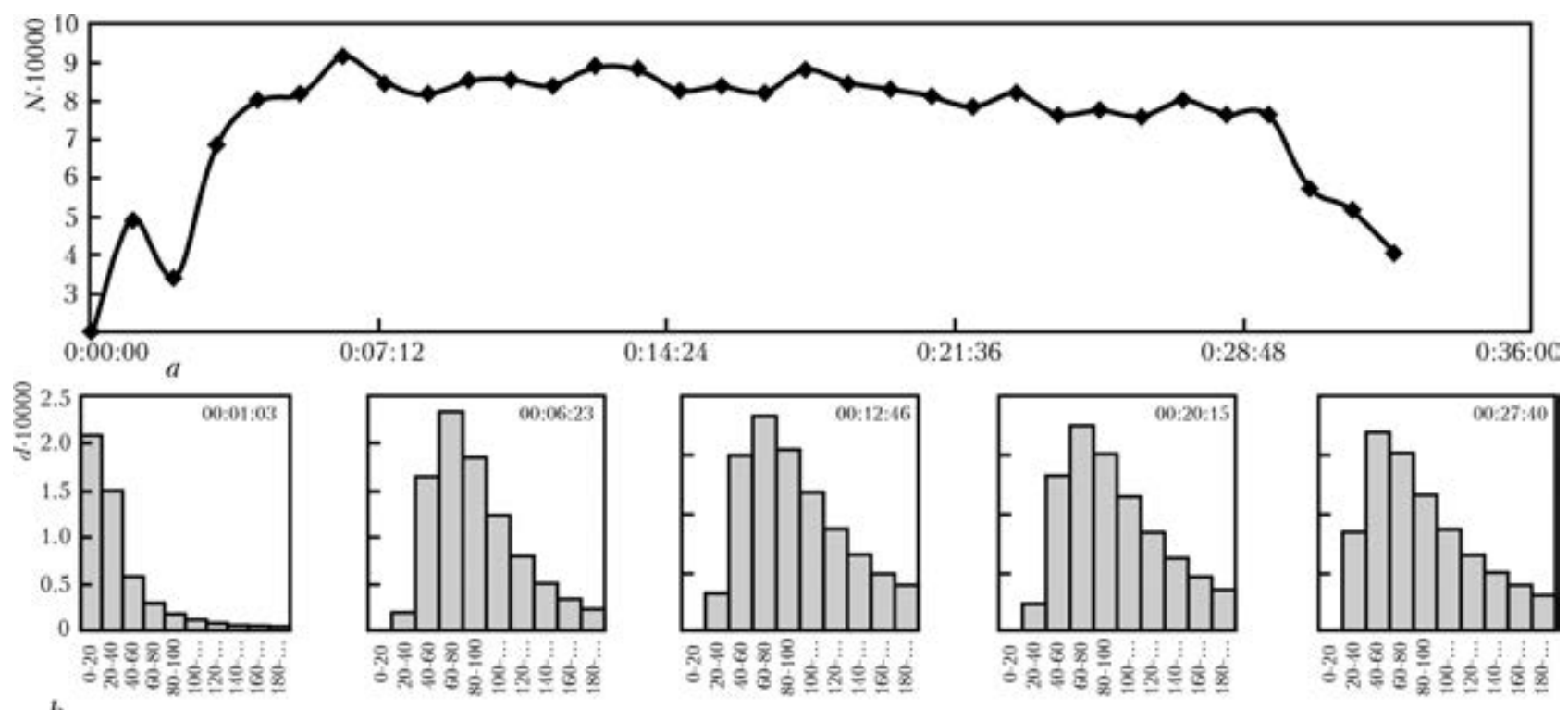

Figure 4. Change in amount of particles $N(a)$ and their size distribution $d$ within time of analysis $(b)$ using DAS 2702 spectrometer 
VIII INTERNATIONAL CONFERENCE «WELDING CONSUMABLES»

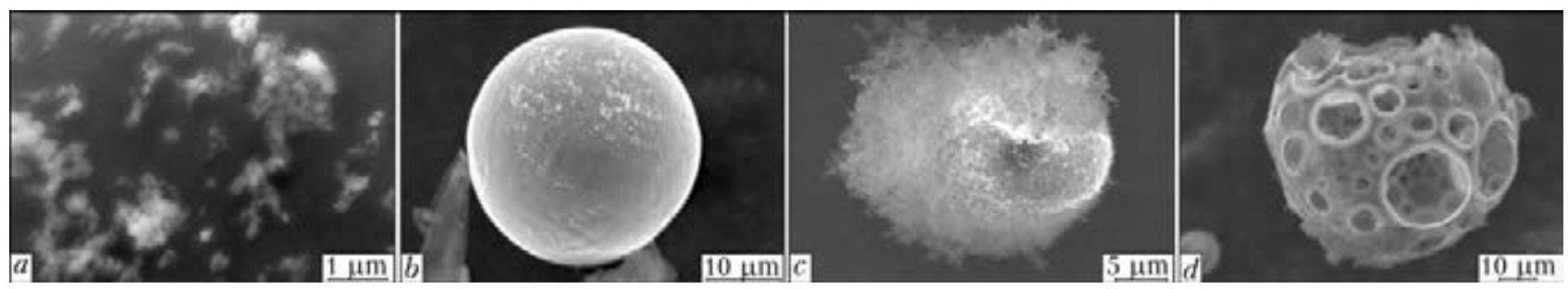

Figure 5. Results of examination of morphology of agglomerates $(a)$ and particles $(b-d)$ of HCWA

of the amount of particles. Before the analysis started, the background amount of particles was determined.

The obtained results (Figure 4) prove that there is a great amount of primary particles of about $20 \mathrm{~nm}$ size in the HCWA immediately upon the start of welding process. As a result of fast agglomerating, their amount increases rapidly, and they are missing in the air flow already after several minutes upon completion of welding. However, the amount of nanosized particles remains high and the spike occurs at the size range of $60-80 \mathrm{~nm}$.

Sampling for investigation of morphology of the HCWA particles was realized by deposition of the latter on the adhesive carbon film, located at the wall of chamber for sampling the HCWA bulk samples at the height of $70 \mathrm{~cm}$ from the welding arc zone. Such an approach allows us not only to obtain the sample with the monolayer of particles, but also to examine their morphology (Figure 5). The examination was carried out in JEOL scanning electron microscopes JSM-35CF and JSM 6490-LA.

The morphology of particles, formed during welding, is heterogeneous. The nanosized particles form agglomerates (Figure 5, $a$ ), which may consist both of several particles, and also of several thousands. There are also coarse round particles, having the size from several micrometers to several tens of micrometers (Figure $5, b$ ). Sometimes they have cavity inside (Figure $5, d$ ), which explains their ability to reach considerable height $(70 \mathrm{~cm})$ in the flow of welding aerosol. Most often, these particles are formed due to metal spattering. Moreover, they are ofteny covered with the layer of nanosized particles (Figure 5, c).

Thus, the results, obtained in course of the HCWA analysis by using different types of equipment and different techniques of preparation of samples and their analysis itself, may diverge considerably. The results, obtained by using the «no-contact» analysis in DAS 2702 spectrometer, may be considered as the most valid ones.

1. Pokhodnya, I.K., Gorpenyuk, V.N., Milichenko, S.S et al. (1990) Metallurgy of arc welding. Processes in arc and melting of electrodes. Ed. by I.K. Pokhodnya. Kiev: Naukova Dumka.
2. (2001) Aerosol measurement: Principles, techniques and applications. 2nd ed. Wiley-Interscience Publ.

3. Sowards, J.W., Lippold, J.C., Dickinson, D.W. et al. (2008) Characterization procedure for the analysis of arc welding fume. Welding $J ., 87,76-83$.

4. Sowards, J.W., Lippold, J.C., Dickinson, D.W. et al. (2008) Characterization of welding fume from SMAW electrodes. Pt 1. Ibid., 87, 106-112.

5. Sowards, J.W., Lippold, J.C., Dickinson, D.W. et al. (2010) Characterization of welding fume from SMAW electrodes. Pt 2. Ibid., 89, 82-89.

6. Hewett, P. (1995) The particle size distribution, density and specific area of welding fumes from SMAW and GMAW mild and stainless steel consumables. Amer. Ind. Hygiene Assoc. J., 56, 128-135.

7. Sterjovski, Z., Norrish, J., Monaghan, B.J. The effect of voltage and metal-transfer mode on particulate-fume size during the GMAW of plain-carbon steel. IIW Doc. VIII-2092-08.

8. Hoet, P.H.M., Brueske-Hohlfeld, I., Salata, O.V. (2004) Nanoparticles known and unknown health risks. J. Nanobiotechnol., 12(2)

9. Raloff, J. (2010) Destination brain. Sci. News, 177(11), 16-20.

10. Glushkova, A.V., Radilov, A.S., Rembovsky, V.R. (2007) Nanotechnologies and nanotoxicology: Opinion on the problem. Toksikolog. Vestnik, 6, 4-8.

11. Elder, A., Gelein, R., Silva, V. (2006) Translocation of inhaled ultrafine manganese oxide particles to the central nervous system. Environ. Health Perspect., 114(8), 1172-1178

12. Simko, M., Fiedeler, U., Gazso, A. et al. (2010) Can nanoparticles end up in the brain. NanoTrust-Dossier, 14.

13. Voitkevich, V. (1995) Welding fumes: Formation, properties and biological effects. Cambridge: Abington Publ.

14. Terjovski, J., Drossier, J., de Thoisy, E. et al. (2006) An investigation of particulate weld fume generated from GMAW of plain carbon steel. Austral. Welding J., 51(1st quart.), 21-40.

15. Worobiec, A., Stefaniak, E.A., Kiro, S. et al. (2007) Comprehensive microanalytical study of welding aerosols with X-ray and Raman based methods. X-Ray Spectrometry, 36, 328-335.

16. Berlinger, B., Benker, N. et al. (2011) Physicochemical characterization of different welding aerosols. Analyt. Bioanalyt. Chemistry, 10, 1773-1780.

17. Zimmer, A.E., Biswas, P. (2001) Characterization of the aerosols resulting from arc welding processes. Aerosol Sci., 32, 993-1008.

18. Kippax, P. (2005) Measuring particle size using modern laser diffraction techniques. Paint \& Coatings Industry, 21, Issue 8, 42.

19. Carpenter, K.R., Monaghan, B.J., Norrish, J. (2009) Analysis of fume formation rate and fume particle composition for gas metal arc welding (GMAW) of plain carbon steel using different shielding gas compositions. ISIJ Int., 49(3), 416-420.

20. Jenkins, N.T., Eager, T.W. (2005) Chemical analysis of welding fume particle. Welding J., 6, 87-93. 